the rapid evolution of the $\mathrm{U}$-series field over the last decade.

\section{Sea level records pre-dating the last glacial cycle}

Prior to the last glacial cycle, the most extensive compilation of $\mathrm{U}$-series observations for fossil coral reefs exists for MIS 7 (Gallup et al., 1994; 2002; Scholz et al., 2006; Thompson and Goldstein, 2005; Dutton et al., this issue), extending from 245-193 ka. Sea level records for MIS 7 are discussed in detail by Dutton et al. (this issue). Furthermore there are a few isolated data points for MIS 6-5 (e.g., Esat et al., 1999; Thomas et al., 2008). Pre-dating MIS 7, the most extensive suite of coral reef U-series observations have been acquired for unusually well-preserved reef complexes formed during MIS 9 (339-303 ka) and MIS 15 (620-570 ka) on Henderson Island, South Pacific Ocean (Stirling et al., 2001; Andersen et al., 2008). Conventional U-series dating of Henderson Island's MIS 9 fossil corals (Fig. 2) indicate that sea levels during MIS 9.3 approached peak interglacial values near $324 \pm 3 \mathrm{ka}$ (Stirling et al., 2001). High sea levels appear to have persisted for a further $8 \mathrm{ka}$, before falling towards glacial values near $318 \pm 3 \mathrm{ka}$ (Stirling et al., 2001). Conventional U-series ages for a single coral tentatively indicate subsequent MIS 9.1 reef growth at $307 \pm$ 4 ka (Stirling et al., 2001). There are also a growing number of high-precision $\mathrm{U}$ series observations for Henderson Island's MIS 15 fossil corals and the results to date indicate peak interglacial sea levels at 600 \pm 15 ka (Andersen et al., 2008). Additional efforts are underway to continue to refine these MIS 9 and 15 sea level chronologies for Henderson Island (e.g., Stirling and Andersen, 2008). Furthermore, Henderson Island is believed to have undergone systematic but non-linear uplift ( 30 m) caused by lithospheric flexure arising from the volcanic emplacement of nearby Pitcairn Island. A combination of flexural uplift and glacio-hydro-isostatic rebound modeling is required to convert the relative sea level observations for Henderson Island into global constraints of eustatic sea level. To date, there is a complete absence of reliable $\mathrm{U}$-series observations for other glacial-interglacial periods. In particular, effort should be expended to identify MIS 11 in the fossil coral record. MIS 11 has been identified as an exceptionally warm and long interglacial in the climate record, characterized by orbital parameters that are similar to those of the today and of the next few millennia (EPICA, 2004), and could represent the most appropriate analog of the present climate system.

Efforts to pursue robust sea level records from fossil corals further back in time should focus on enhancing the precision and accuracy of the U-series chronometer.
Furthermore, an improved understanding of the mechanisms involved in the opensystem loss/gain of the U-series isotopes during the post-depositional diagenetic alteration of fossil reef systems (see Andersen et al., this issue) is critical to ensure the reliability of $\mathrm{U}$-series ages dated both conventionally and via the implementation of open-system methods. Moreover, it is important to augment the fossil coral records with U-series observations for complementary archives of past sea level change, particularly submerged speleothems (Bard et al., 2002; Dutton et al., this issue) and aragonitic slope sediments (Henderson et al., 2006).

\section{References}

Andersen, M.B., Stirling, C.H., Potter, E.K., Halliday, A.N., Blake, S.G., McCulloch, M.T., Ayling, B.F. and O'Leary, M., 2008: High-precision U-series measurements of more than 500,000 year old fossil corals, Earth and Planetary Science Letters, 265: 229-245.

Edwards, R.L., Cutler, K.B., Cheng, H. and Gallup, C.D., 2003: Geochemical Evidence for Quaternary Sea-level Changes. In: Turekian, K.K. and Holland, H.D. (Eds) Treatise on Geochemistry, Elsevier, 6.13 343-364.

Goldstein, S.J. and Stirling, C.H., 2003: Techniques for measuring uranium-series nuclides: 1992-2002. In: Bourdon, B. et al., (Eds) Reviews in Mineralogy and Geochemistry, Geochemical Society, 52: 23-57.

Stirling, C.H., Esat, T.M., Lambeck, K., McCulloch, M.T., Blake, S.G., Lee, D.-C. and Halliday, A.N., 2001: Orbital forcing of the Marine Isotope Stage 9 interglacial, Science, 291: 290-293.

Thompson, W.G. and Goldstein, S.L., 2005: Open-system coral ages reveal persistent suborbital sea-level cycles, Science, 308: 401404.

\title{
Ice sheet retreat and sea level rise during the last deglaciation
}

Peter U. Clark

Department of Geosciences, Oregon State University, Corvallis, USA; clarkp@onid.orst.edu

\section{The terrestrial record of deglaciation provides important constraints on the relative contribution of individual ice sheets to global sea level rise, thus improving our ability to estimate sea level sensitivity to climate change.}

The Last Glacial Maximum (LGM) is conventionally defined as the most recent interval in Earth's history when global ice sheets reached their maximum integrated volume. Documenting the rate of retreat of the global ice sheets following the LGM provides important insights towards understanding the sensitivity of ice sheet retreat and associated sea level rise to climate forcing. Additionally, a number of feedbacks associated with ice sheet retreat, including changes in albedo, orography, and freshwater fluxes to sites of deepwater formation, significantly influenced the trajectory and rate of deglaciation at regional to global scales.
The record of global sea level rise during the last deglaciation is best constrained from geomorphic and biological indicators of sea level at sites far from glaciated areas (far-field sites). Because sea level is an integrated signal, however, it does not distinguish between the relative contributions of individual ice sheets to the global signal, including growth of an ice sheet during the global deglaciation. Moreover, although the rate of sea level rise reveals changes in the total freshwater flux to the ocean associated with melting, it does not indicate how changes in the distribution of that flux to different regions of the ocean may have occurred solely from the rerouting of runoff, which may be just as important in influencing density-driven changes in ocean circulation as changes in the total flux.

Combining the terrestrial record of ice sheet retreat with the sea level record during the last deglaciation provides a complimentary strategy to address important aspects of ice sheet-climate interactions. Radiocarbon and cosmogenic surface exposure ages allow the position of retreating ice sheet margins to be mapped through the deglaciation, thus constraining rates of retreat (or readvance) for individual ice sheets as well as the opening (or closing) of outlets that route subcon- 

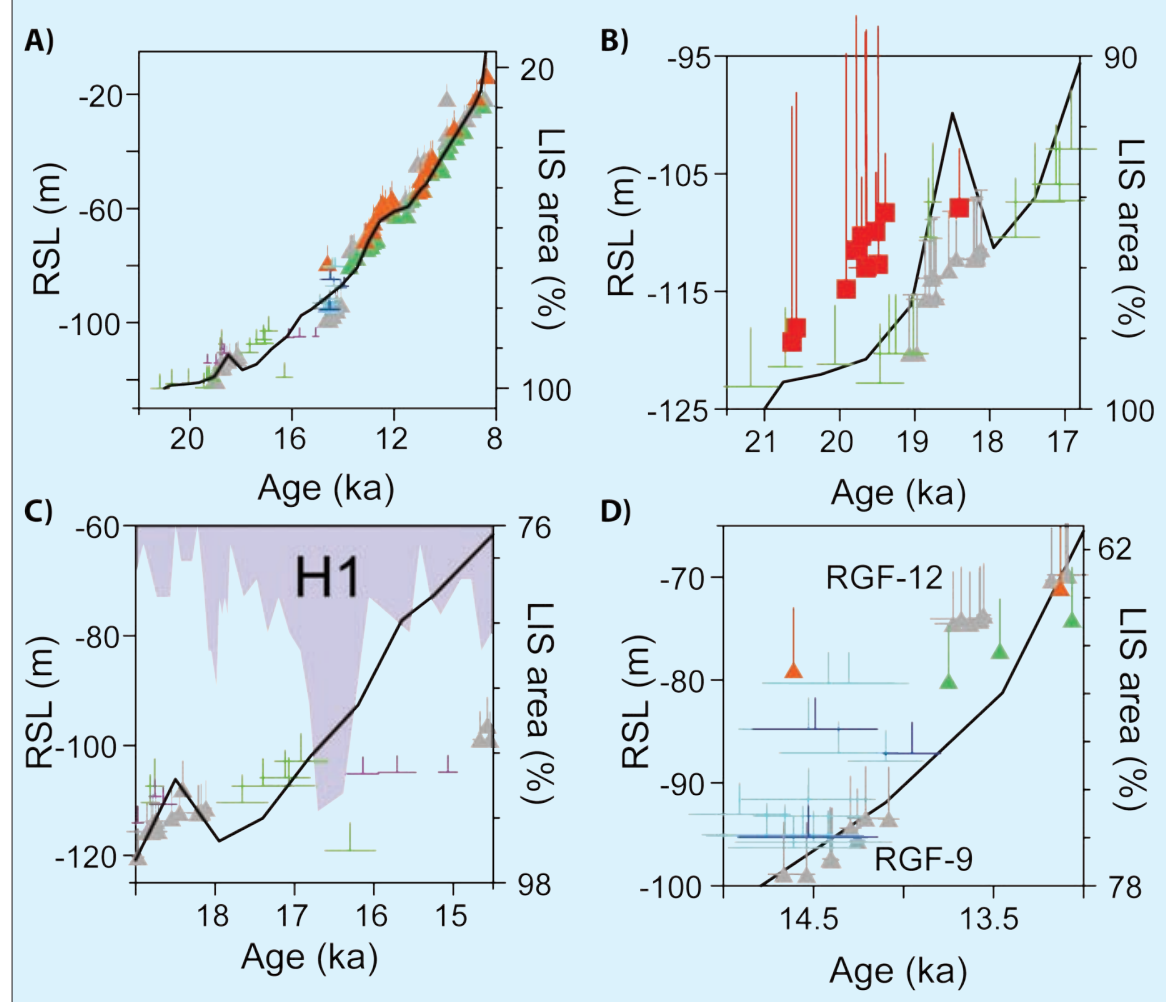

Figure 1: $\boldsymbol{A})$ The last deglaciation relative sea level record (RSL) reconstructed from geomorphic and biological indicators at sites far from the former large ice sheets and compared to the retreat of the Laurentide Ice Sheet (LIS; black line) (Dyke, 2004). Symbols are coded to individual sites as follows: Green lines are Bonaparte Gulf calibrated ${ }^{14} \mathrm{C}$ ages (Yokoyama et al., 2000) showing age and depth uncertainty, Gray diamonds are U/Th ages on Barbados corals from core RGF-9 (Bard et al., 1993; Peltier and Fairbanks, 2006). Sunda Shelf calibrated ${ }^{14} \mathrm{C}$ ages are shown as pink lines (non-mangrove organics), light blue lines (mangrove remains, not in situ), and dark blue lines (mangrove remains in situ) (Hanebuth et al., 2000), Orange triangles are U/Th ages on corals from New Guinea (Edwards et al., 1993: ( Cutler et al., 2003), Light green triangles are U/Th ages on corals from Tahiti (Bard et al., 1996). B) Detail of sea level history and LIS deglaciation between $21.5 \mathrm{ka}$ and $16.8 \mathrm{ka}$, using same symbols as in A). Also shown are Barbados corals from core RGF-15 (red squares), including the species Montastrea annularis (Peltier and Fairbanks, 2006). C) Detail of sea level history and LIS deglaciation between $19 \mathrm{ka}$ and $14.5 \mathrm{ka}$ using same symbols as in A). Also shown is the $\mathrm{CaCO}_{3}$ component of ice-rafted debris, showing a peak at the time of Heinrich event $1(\mathrm{H} 1$; Bond et al., 1999). D) Detail of sea level history and LIS deglaciation between $15 \mathrm{ka}$ and $13 \mathrm{ka} \mathrm{using} \mathrm{same} \mathrm{symbols} \mathrm{as} \mathrm{in}$ A). The Barbados coral samples from cores RGF-9 and RGF-12 are identified.

tinental drainage basins from one river to another. Although the detailed retreat history of some ice sheets remains poorly known, there is sufficient information to identify the first-order aspects of their retreat that are important to the sea level record, such as their contributions to the termination of the LGM lowstand or subsequent episodes of rapid sea level rise (Clark et al., submitted). An important caveat in using the land record to constrain sea level is that it only represents area, not volume, but to first-order, modern relationships suggest that ice sheet extent scales with volume (Paterson, 1994).

Here, I use this complementary strategy to infer the primary ice sheet contributions to the first-order structure of global sea level rise during the last deglaciation. In particular, I focus on the interval between 21 and $13 \mathrm{ka}$, during which time a large fraction of sea level rise occurred in two relatively brief steps (Fig. 1a). The first step is identified from data from Bonaparte Gulf (Yokoyama et al., 2000) and the Irish Sea basin (Clark et al., 2004), which suggest that the LGM lowstand other Northern Hemisphere ice sheets also started to retreat between 19-20 ka (Clark et al., submitted), further supporting the younger age for this event, and identifying the Northern Hemisphere ice sheets as its primary source.

Between 19 and $\sim 14.5 \mathrm{ka}$, rates of sea level rise decreased substantially $(<3.5 \mathrm{~mm}$ $\mathrm{a}^{-1}$ ) (Fig. 1c). The LIS and the Scandinavian
Ice Sheet, however, continued to retreat throughout this interval (Rinterknecht et al., 2006; Clark et al., submitted), and Heinrich event $1(\mathrm{H} 1)$ also occurred at $\sim 17$ ka (Fig. 1c), all suggesting some sea level rise. The fact that existing data indicate little sea level rise thus suggests that one or more other ice sheets must have grown at a rate that nearly balanced the mass loss from these two ice sheets. The southern margin of the Cordilleran Ice Sheet ( $\mathrm{N}$ America) advanced to its maximum extent between $19 \mathrm{ka}$ and $17.5 \mathrm{ka}$ (Porter and Swanson, 1998) but its growth likely represented a small contribution to sea level. The Barents-Kara Ice Sheet had largely collapsed by 19 ka (Svendsen et al., 2004). Accordingly, the only remaining large ice sheets that could offset the sea level rise associated with retreat of the two largest Northern Hemisphere ice sheets were the Antarctic Ice Sheets but there are currently insufficient geochronologic constraints to test this hypothesis.

Sea level subsequently rose rapidly again during meltwater pulse $1 \mathrm{~A}$ (mwp$1 A)$, when as much as $20 \mathrm{~m}$ of rise occurred in less than 500 years (Fig. 1d). Two aspects of this event have been widely discussed: its age, and thus relation to climate change, and its source. With respect to the former, Stanford et al. (2006) argued that it occurred between the youngest dated coral in Barbados core RGF-9 (14.1 ka) and the oldest coral in core RGF-12 (13.6 ka), and dismissed the Sunda Shelf ${ }^{14} \mathrm{C}$ ages that suggest an older age for mwp-1A (Fig. 1d) because of uncertainties in correcting for variable ${ }^{14} \mathrm{C}$ reservoir ages. The key Sunda Shelf ${ }^{14} \mathrm{C}$ ages that constrain the timing of mwp-1A, however, are on fragments of mangrove trees, which are not subject to reservoir age corrections. Moreover, the older age for mwp-1A is supported by a U/ Th age on a coral from New Guinea (Fig. 1d) (Cutler et al., 2003). One explanation for this discrepancy in timing is that the shallow-water corals sampled in core RGF9 were unable to "keep up" with the rapid sea level rise of mwp-1A, and eventually "gave up" (Neumann and Mcintyre, 1985), with the establishment of a new shallowwater coral reef, sampled by core RGF-12, only after sea level rise had sufficiently slowed.

Possible sources of mwp-1A have been widely discussed (e.g., Bassett et al., 2005; Clark et al., 1996; 2002; Peltier, 2005). There are several key reasons why a significant contribution from the Northern Hemisphere is unlikely: (1) Peltier (1994; 2005) argued for a significant contribution from the LIS but there is no acceleration in its rate of retreat during $\mathrm{mwp}-1 \mathrm{~A}$ relative 
to before and after (Fig. 1a, 1d). (2) Peltier (2005) argued that the Barents-Kara Ice Sheet also contributed to the event but this ice sheet had largely deglaciated by 19 ka (Svendsen et al., 2004). (3) Ocean models consistently demonstrate that the freshwater flux to the North Atlantic from a Northern Hemisphere source would have shut down the Atlantic meridional overturning circulation (AMOC), which did not occur (McManus et al., 2004). Aharon (2006) argued that benthic $\delta^{18} \mathrm{O}$ records from the Gulf of Mexico support a substantial contribution from the LIS with minimal effect on the AMOC but Carlson (2009) showed that aspects of the model used by Aharon (2006) were incorrect.

In contrast, a substantial contribution from Antarctica explains why there is no significant reduction in the $\mathrm{AMOC}$, and instead may explain why the AMOC abruptly resumed at this time (Weaver et al., 2003; Pahnke et al., 2008). In addition, an Antarctic source explains the geographic variation in far-field sea level records associated with the processes of glacial isostatic adjustment (Clark et al., 2002; Bassett et al., 2005).

In summary, the terrestrial record of past changes in global ice sheets places important constraints in identifying their contributions to the sea level rise of the last deglaciation. In particular, multiple ice sheets represent multiple reservoirs, each potentially behaving independently of each other in response to regional or hemispheric climate change. As is the case for modern ice sheets and future sea level change, disentangling these contributions is critical to fully decipher the sensitivity of sea level to climate change.

\section{References}

Bassett, S.E., Milne, G.A., Mitrovica, J.X. and Clark, P.U., 2005: Ice sheet and solid earth influences on far-field sea level histories, Science, 309: 925-928.

Clark, P.U., Mitrovica, J.X., Milne, G.A. and Tamisiea, M., 2002: Sea level fingerprinting as a direct test for the source of global meltwater pulse IA, Science, 295: 2438-2441.

Clark, P.U., McCabe, A.M., Mix, A.C. and Weaver, A.J., 2004: The 19-kyr B.P. meltwater pulse and its global implications, Science, 304: 1141-1144.

Dyke, A.S., 2004: An outline of North American Deglaciation with emphasis on central and northern Canada, In: Ehlers, J. and Gibbard, P.L. (Eds), Quaternary Glaciations: Extent and Chronology, Elsevier, 373-424.

Milne, G.A. and Mitrovica, J.X., 2008: Searching for eustasy in deglacia sea level histories, Quaternary Science Reviews, 27: 2292-2302.

For full references please consult:

www.pages-igbp.org/products/newsletters/ref2009_2.html

\section{A new chronology of sea level highstands for the penultimate interglacial}

Andrea Dutton', F. Antonioli² and E. Bard ${ }^{3}$

${ }^{1}$ Research School of Earth Sciences, Australian National University, Canberra; andrea.dutton@anu.edu.au

2Italian National Agency for New Technologies, Energy and Environment, Rome, Italy; ${ }^{3}$ European Center for Research and Teaching of Geosciences and the Environment, National Center of Scientific Research and Aix-Marseille University, College de France, Aix-en-Provence, France

\section{A suite of submerged Italian speleothems constrain the timing of sea level highstands across the entirety of marine isotope stage 7 ( 190-245 ka) indicating that sea level highstands were broadly in phase with insolation forcing.}

Understanding the precise phase relationships of changes in sea level, temperature, and greenhouse gas concentrations during previous interglacials provides us with critical knowledge to evaluate the future response of the climate system to anthropogenic forcing. Absolutely dated sea level archives that document the response of ice sheets to changes in temperature and atmospheric $\mathrm{CO}_{2}$ become increasingly rare as we look beyond the last interglacial (ca. $130 \mathrm{ka}$ ) due to the combined effects of alteration of suitable archives, physical superposition of multiple sea level oscillations, and challenges related to temporal limitations of geochronometers. This leads us to rely upon sea level reconstructions that are derived from deep-sea cores and models, which both lack direct age control. Because we seek to understand the phasing of orbital forcing and climate records relative to more continuous records of sea level change that are available from these models and deep-sea cores, we must first calibrate these against absolutely dated records of sea level response.

We have studied a suite of submerged stalagmites from Argentarola Cave (central west coast of Italy) collected across a depth range of -18 to $-21 \mathrm{~m}$, with the aim

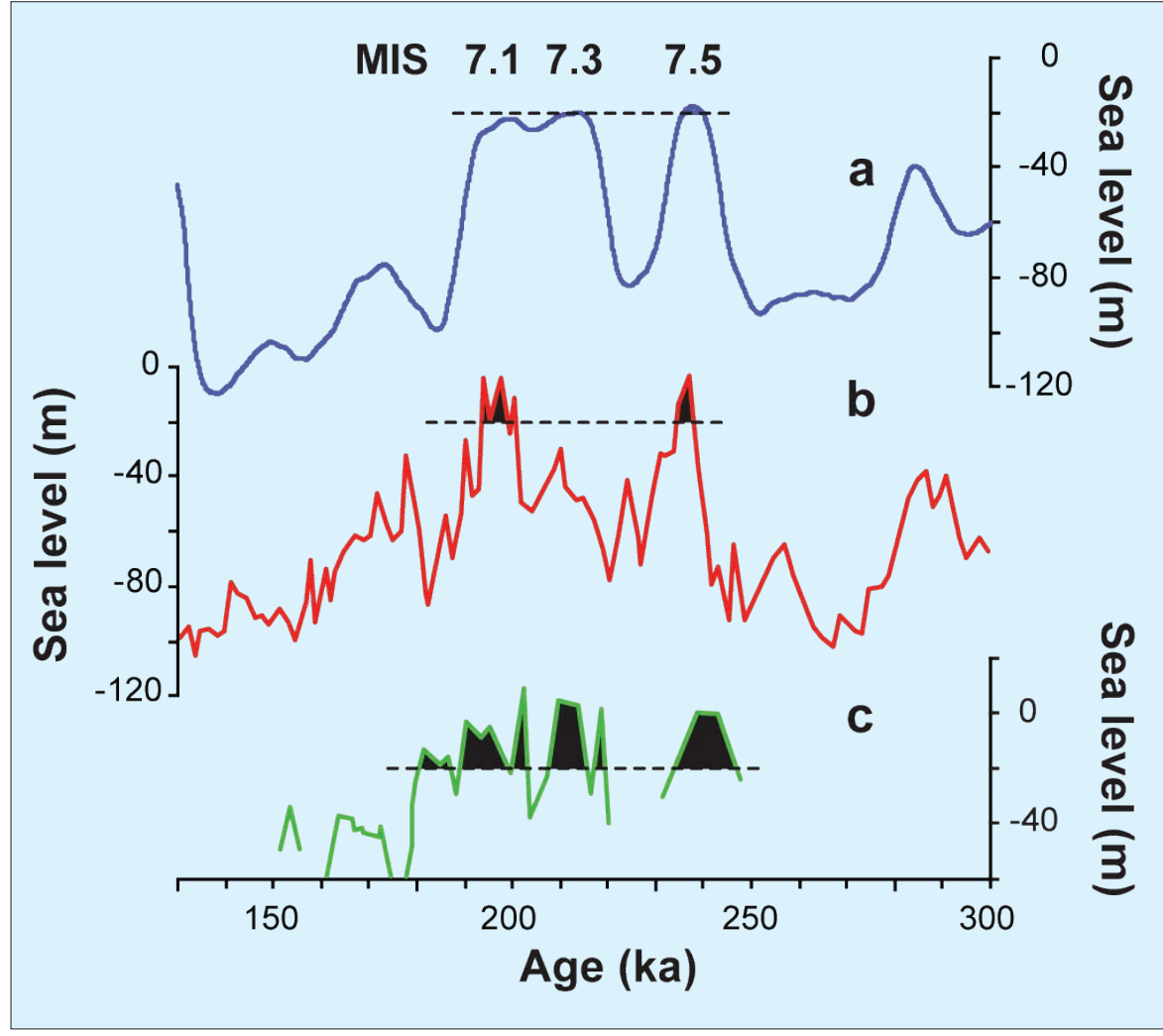

Figure 1: Sea level curves shown for MIS 7, derived using three different methods: (a) model (Bintanja et al., 2008) driven by benthic oxygen isotope $\left(\delta^{18} \mathrm{O}\right)$ stack, (b) reconstruction of Red Sea seawater $\delta^{18} \mathrm{O}$ (Siddall et al., 2003), (c) open system U-Th ages of corals (Thompson and Goldstein, 2005). Shading indicates periods of time that sea level rose above-20 m (dashed lines), the approx. depth of Argentarola Cave stalagmites. Note differences in the number of highstands predicted to exceed $-20 \mathrm{~m}$ and the difference in elevation predicted for MIS 7.3 in particular. Figure modified from Dutton et al., 2009. 